\section{Case Report}

D) Check for updates

\section{Motor Recovery after Seizure Induced by Repetitive Transcranial Magnetic Stimulation}

Received: Feb 23, 2019

Revised: Mar 14, 2019

Accepted: Mar 19, 2019

Correspondence to

Yoon Ghil Park

Department of Rehabilitation Medicine,

Gangnam Severance Hospital, Yonsei

University, 20 Eonju-ro 63-gil, Gangnam-gu,

Seoul 06229, Korea

E-mail: DRTLC@yuhs.ac
Jinyoung Park, Young Seok Kim, Eu Jeong Ko, Yoon Ghil Park

\section{HIGHLIGHTS}

- This is the first report of motor recovery after a seizure induced by high-frequency repetitive transcranial magnetic stimulation (rTMS).

- The hand strength and coordination were improved after seizure induced by rTMS.

- Rarely, neurologic recoveries are reported rather than deteriorations after seizures. 


\section{Case Report}

Check for updates

\title{
Motor Recovery after Seizure Induced by Repetitive Transcranial Magnetic Stimulation
}

\author{
Jinyoung Park (D), Young Seok Kim (D), Eu Jeong Ko (D), Yoon Ghil Park (D) \\ Department of Rehabilitation Medicine, Gangnam Severance Hospital, Rehabilitation Institute of \\ Neuromuscular Disease, Yonsei University College of Medicine, Seoul, Korea
}

\section{Received: Feb 23, 2019 \\ Revised: Mar 14, 2019 \\ Accepted: Mar 19, 2019 \\ Correspondence to \\ Yoon Ghil Park \\ Department of Rehabilitation Medicine, \\ Gangnam Severance Hospital, Yonsei \\ University, 20 Eonju-ro 63-gil, Gangnam-gu, \\ Seoul 06229, Korea. \\ E-mail: DRTLC@yuhs.ac}

Copyright (c) 2019. Korea Society for

Neurorehabilitation

This is an Open Access article distributed under the terms of the Creative Commons Attribution Non-Commercial License (https:// creativecommons.org/licenses/by-nc/4.0) which permits unrestricted non-commercial use, distribution, and reproduction in any medium, provided the original work is properly cited.

\section{ORCID iDs}

Jinyoung Park (D)

https://orcid.org/0000-0003-4042-9779 Young Seok Kim (D)

https://orcid.org/0000-0002-6315-5216

Eu Jeong Ko (D)

https://orcid.org/0000-0001-8796-9655 Yoon Ghil Park (iD)

https://orcid.org/0000-0001-9054-5300

Conflict of Interest

The authors have no potential conflicts of interest to disclose.

\begin{abstract}
Despite the low incidence, seizures induced by repetitive transcranial magnetic stimulation (rTMS) have been studied as they may cause neurological and functional regression. Seizures may predict poor outcomes in stroke patients, with no reports of improved neurological status after seizures. This is the first Korean report of a seizure induced by rTMS, and the first report in the literature of prompt motor recovery following a seizure induced by highfrequency rTMS of the primary motor cortex in a stroke patient. A 43-year-old man with left hemiplegia due to infarction in the right basal ganglia was enrolled 10 sessions of rTMS (each session consisted of 15 trains, with each train consisting of 5 seconds of stimulation at 20 $\mathrm{Hz}$ and $90 \%$ of resting motor threshold for each session followed by 55 seconds of rest). The self-limited seizure occurred within 5 seconds after the 10th session. It lasted for 60 seconds, with generalized tonic features in all four extremities and the trunk and loss of consciousness followed by prompt improvement in left hand muscle strength and coordination. Though the seizure is known to usually cause neurologic regression, this case showed neurologic improvement after rTMS even after the rTMS-induced seizure.
\end{abstract}

Keywords: Transcranial Magnetic Stimulation; Seizures; Muscle Strength; Stroke

\section{INTRODUCTION}

Since its introduction in 1984, repetitive transcranial magnetic stimulation (rTMS) has been studied in patients with stroke, spinal cord injury, depression, epilepsy, and pain, and some results remain controversial. There has also been extensive discussion on ethical issues and safety. With focus on motor recovery after stroke, protocols are generally divided into highfrequency and low-frequency rTMS. Low-frequency rTMS at $1 \mathrm{~Hz}$ inhibits the brain cortex, and high-frequency rTMS at $10 \mathrm{~Hz}$ or more stimulates the cortex. Thus, seizures have been among the concerning adverse effects of high-frequency rTMS, but not many cases have been reported. This is the first report in the literature of prompt motor recovery and improved motor coordination following a seizure provoked by high-frequency rTMS of the primary motor cortex. 


\section{CASE REPORT}

A 43-year-old man had sudden dysarthria with left upper and lower extremity weakness on March 7, 2016. He arrived in the emergency room 1 hour after onset. He was alert, with no epileptic activity or loss of consciousness. Manual muscle testing showed poor minus grade to poor plus grade in left side (Table 1). He could not move his left thumb opposite to the second-fifth fingers. He also had a sensory deficit to light touch, pain, temperature, and proprioception on his left side. After the computed tomography (CT) revealed intracerebral hemorrhage ( $\mathrm{ICH}$ ) in the right basal ganglia (Fig. 1), he was admitted to the Department of Neurosurgery. Intravenous mannitol was promptly started. Oral levetiracetam to prevent post-hemorrhagic seizure was started with $1,000 \mathrm{mg} /$ day next day. As CT angiography 6 hours after the initial scan revealed no interval change in the amount of hemorrhage or a midline shift, he was treated without surgery. Brain magnetic resonance image on the seventh day after onset showed focal left distal vertebral arterial stenosis with subacute ICH in the right basal ganglia. On the transfer day to the Department of Physical Medicine and Rehabilitation on March 19, the motor grades of the left shoulder and elbow were to poor plus, and thus, he needed moderate assistance with activities of daily living. He was enrolled in a rehabilitation program including physical therapy for strengthening and gait training, and occupational therapy to improve hand function. When examined on March 28, he showed fair grade in the left upper extremity, except for fair minus grade in left finger flexion and extension, and fair minus grade in the left lower extremity. As he had no seizure or seizure-like events, we gradually reduced the dosage of levetiracetam to $500 \mathrm{mg}$ /day on March 26, $250 \mathrm{mg}$ /day on April 6, and tapered off by April 11.

Table 1. Serial manual muscle testing and the Medical Research Council scales

\begin{tabular}{|c|c|c|c|c|c|c|c|c|}
\hline \multirow[t]{2}{*}{ Region } & \multicolumn{4}{|c|}{ Before the seizure } & \multicolumn{4}{|c|}{ After the seizure } \\
\hline & 03.08.2016 & 03.19.2016 & 03.28 .2016 & 04.16 .2016 & 04.18 .2016 & 04.19 .2016 & 04.21 .2016 & 06.21 .2016 \\
\hline \multicolumn{9}{|c|}{ Shoulder } \\
\hline $\mathrm{Fl}$ & $\mathrm{N} / \mathrm{P}$ & $\mathrm{N} / \mathrm{P}+$ & $\mathrm{N} / \mathrm{F}$ & $\mathrm{N} / \mathrm{F}$ & $\mathrm{N} / \mathrm{F}$ & $\mathrm{N} / \mathrm{F}$ & $\mathrm{N} / \mathrm{F}$ & $N / G$ \\
\hline Ex & $\mathrm{N} / \mathrm{P}$ & $\mathrm{N} / \mathrm{P}+$ & $\mathrm{N} / \mathrm{F}$ & $\mathrm{N} / \mathrm{F}$ & $\mathrm{N} / \mathrm{F}$ & $\mathrm{N} / \mathrm{F}$ & $\mathrm{N} / \mathrm{F}$ & $N / G$ \\
\hline$A b$ & $\mathrm{~N} / \mathrm{P}$ & $\mathrm{N} / \mathrm{P}+$ & $\mathrm{N} / \mathrm{F}$ & $\mathrm{N} / \mathrm{F}$ & $\mathrm{N} / \mathrm{F}$ & $\mathrm{N} / \mathrm{F}$ & $\mathrm{N} / \mathrm{F}$ & $N / G$ \\
\hline$A d$ & $\mathrm{~N} / \mathrm{P}$ & $\mathrm{N} / \mathrm{P}+$ & $\mathrm{N} / \mathrm{F}$ & $\mathrm{N} / \mathrm{F}$ & $\mathrm{N} / \mathrm{F}$ & $\mathrm{N} / \mathrm{F}$ & $\mathrm{N} / \mathrm{F}$ & $N / G$ \\
\hline \multicolumn{9}{|l|}{ Elbow } \\
\hline $\mathrm{Fl}$ & $\mathrm{N} / \mathrm{P}$ & $\mathrm{N} / \mathrm{P}+$ & $N / F$ & $\mathrm{~N} / \mathrm{F}$ & $\mathrm{N} / \mathrm{F}$ & $\mathrm{N} / \mathrm{F}$ & $N / F$ & $N / G$ \\
\hline Ex & $N / P$ & $\mathrm{~N} / \mathrm{P}+$ & $N / F$ & $N / F$ & $N / F$ & $N / F$ & $N / F$ & $N / G$ \\
\hline \multicolumn{9}{|l|}{ Wrist } \\
\hline $\mathrm{Fl}$ & $\mathrm{N} / \mathrm{P}+$ & $\mathrm{N} / \mathrm{P}+$ & $\mathrm{N} / \mathrm{F}$ & $\mathrm{N} / \mathrm{F}$ & $\mathrm{N} / \mathrm{F}$ & $\mathrm{N} / \mathrm{F}$ & $\mathrm{N} / \mathrm{F}$ & $N / G$ \\
\hline Ex & $\mathrm{N} / \mathrm{P}+$ & $\mathrm{N} / \mathrm{P}+$ & $\mathrm{N} / \mathrm{F}$ & $\mathrm{N} / \mathrm{F}$ & $\mathrm{N} / \mathrm{F}$ & $\mathrm{N} / \mathrm{F}$ & $\mathrm{N} / \mathrm{F}$ & $N / G$ \\
\hline \multicolumn{9}{|l|}{ Finger } \\
\hline $\mathrm{Fl}$ & $\mathrm{N} / \mathrm{P}+$ & $\mathrm{N} / \mathrm{P}+$ & $\mathrm{N} / \mathrm{F}-$ & $\mathrm{N} / \mathrm{F}-$ & $N / G^{*}$ & $\mathrm{~N} / \mathrm{F}^{+}{ }^{+}$ & $\mathrm{N} / \mathrm{F}+$ & $N / G$ \\
\hline Ex & $\mathrm{N} / \mathrm{P}+$ & $\mathrm{N} / \mathrm{P}+$ & $\mathrm{N} / \mathrm{F}-$ & $\mathrm{N} / \mathrm{F}-$ & $\mathrm{N} / \mathrm{F}+{ }^{*}$ & $\mathrm{~N} / \mathrm{F}+$ & $\mathrm{N} / \mathrm{F}+$ & $N / G$ \\
\hline \multicolumn{9}{|l|}{ Hip } \\
\hline $\mathrm{Fl}$ & $N / P$ & $\mathrm{~N} / \mathrm{P}-$ & $\mathrm{N} / \mathrm{F}-$ & $\mathrm{N} / \mathrm{F}-$ & $N / F^{*}$ & $\mathrm{~N} / \mathrm{F}$ & $N / F$ & $\mathrm{~N} / \mathrm{G}$ \\
\hline Ex & $\mathrm{N} / \mathrm{P}$ & $\mathrm{N} / \mathrm{P}-$ & $\mathrm{N} / \mathrm{F}-$ & $\mathrm{N} / \mathrm{F}-$ & $N / F^{*}$ & $\mathrm{~N} / \mathrm{F}$ & $\mathrm{N} / \mathrm{F}$ & $N / G$ \\
\hline$A b$ & $\mathrm{~N} / \mathrm{P}$ & $\mathrm{N} / \mathrm{P}-$ & $\mathrm{N} / \mathrm{F}-$ & $\mathrm{N} / \mathrm{F}-$ & $N / F^{*}$ & $\mathrm{~N} / \mathrm{F}$ & $\mathrm{N} / \mathrm{F}$ & $N / G$ \\
\hline $\mathrm{Ad}$ & $N / P$ & $\mathrm{~N} / \mathrm{P}-$ & $\mathrm{N} / \mathrm{F}-$ & $\mathrm{N} / \mathrm{F}-$ & $N / F^{*}$ & $\mathrm{~N} / \mathrm{F}$ & $\mathrm{N} / \mathrm{F}$ & $N / G$ \\
\hline \multicolumn{9}{|l|}{ Knee } \\
\hline $\mathrm{Fl}$ & $N / P$ & $\mathrm{~N} / \mathrm{P}-$ & $\mathrm{N} / \mathrm{F}-$ & $\mathrm{N} / \mathrm{F}-$ & $N / F^{*}$ & $\mathrm{~N} / \mathrm{F}$ & $N / F$ & $\mathrm{~N} / \mathrm{G}$ \\
\hline Ex & $N / P$ & $\mathrm{~N} / \mathrm{P}-$ & $\mathrm{N} / \mathrm{F}-$ & $\mathrm{N} / \mathrm{F}-$ & $N / F^{*}$ & $\mathrm{~N} / \mathrm{F}$ & $\mathrm{N} / \mathrm{F}$ & $N / G$ \\
\hline \multicolumn{9}{|l|}{ Ankle } \\
\hline Df & $\mathrm{N} / \mathrm{P}-$ & $\mathrm{N} / \mathrm{P}-$ & $\mathrm{N} / \mathrm{F}-$ & $\mathrm{N} / \mathrm{F}-$ & $\mathrm{N} / \mathrm{F}-$ & $\mathrm{N} / \mathrm{F}-$ & $\mathrm{N} / \mathrm{F}-$ & $\mathrm{N} / \mathrm{G}$ \\
\hline Pf & $\mathrm{N} / \mathrm{P}-$ & $\mathrm{N} / \mathrm{P}-$ & $\mathrm{N} / \mathrm{F}-$ & $\mathrm{N} / \mathrm{F}-$ & $\mathrm{N} / \mathrm{F}-$ & $\mathrm{N} / \mathrm{F}-$ & $\mathrm{N} / \mathrm{F}-$ & $\mathrm{N} / \mathrm{G}$ \\
\hline
\end{tabular}

Fl, flexion; Ex, extension; Ab, abduction; Ad, adduction; Df, dorsiflexion; Pf, plantar flexion; N, normal; G, good; F+, fair plus; F, fair; F-, fair minus; P+, poor plus; P, poor; $\mathrm{P}-$, poor minus.

${ }^{*}$ Prompt increase in muscle power after post-ictal state on the day the seizure occurred; ${ }^{+}$Decrease in power 1 day after the seizure, but still increased compared to before the seizure. 


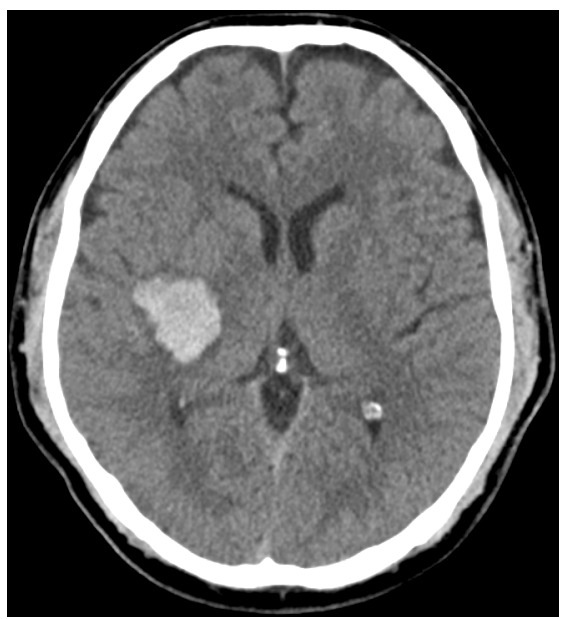

Fig. 1. Brain computed tomography revealed intracerebral hemorrhage in the right basal ganglia.

High-frequency rTMS was started on April 4, and the last of the 10 sessions was completed on April 18. The patient was placed in a stable and comfortable position in a chair, and fixed posture was maintained throughout the procedure. Stimulation was applied using a figureeight coil, MC-B70 (MagVenture, London, UK) connected to MagPro R30 (MagVenture), positioned over the primary motor hot spot of the affected hemisphere. Each session consisted of 15 trains, and each train consisted of 5 seconds at $20 \mathrm{~Hz}$ and $90 \%$ of the resting motor threshold (RMT) stimulations followed by 55 seconds of rest. The RMT was defined as the minimum stimulatory intensity necessary to elicit $>50 \mu \mathrm{V}$ of motor response in the right abductor digiti minimi muscle on 5 out of 10 consecutive trials. The measured RMT was $60 \%$ of maximum coil output. When stimulated with $90 \%$ RMT, the right cortex showed maximum $0.2 \mathrm{mV}$ of amplitude/minimum $24.8 \mathrm{~ms}$ of onset latency, where the left cortex showed maximum $2.3 \mathrm{mV} / 21.3 \mathrm{~ms}$. It was performed by one skilled physician. At each session, he was observed for 15 minutes to confirm stability without complications.

The Medical Research Council scale was used by one physician to assess muscle power. Thumb opposition was used to evaluate fine motor function, and the Kapandji score was determined for each evaluation. Power was measured with a hand dynamometer and pinch gauge (Baseline $^{\oplus}$; Fabrication Enterprises, Inc., New York, NY, USA) by one skilled occupational therapist. In addition to these objective tests, patient's own report was also considered.

\section{Seizure induced by rTMS}

The seizure occurred within 5 seconds after finishing the 10th session of rTMS. The patient showed generalized tonic features in all four extremities with loss of consciousness. The head was turned to the right, and the eyeballs were deviated to the right. The self-limited seizure lasted 60 seconds. Brain CT only showed the old focal lesion in the right basal ganglia. Oral levetiracetam of $500 \mathrm{mg} /$ day restarted. Electroencephalography (EEG) evaluated on the day of seizure was normal, with no interictal epileptiform discharge. He kept the medication for 2 weeks and quit by himself after discharge, but there was no additional seizure event over 2 years. The following EEG evaluated 2 years after the seizure also showed normal.

\section{Functional gain after seizure induced by rTMS}

After the post-ictal state passed, he reported that he could make a left fist within 10 seconds before the seizure, for the first time since the stroke. Neurologic examination 6 hours after 
Table 2. Hand power and function

\begin{tabular}{|c|c|c|c|c|c|}
\hline \multirow[t]{2}{*}{ Variables } & \multicolumn{2}{|c|}{ Before the seizure } & \multicolumn{3}{|c|}{ After the seizure } \\
\hline & 03.15 .2016 & 04.16 .2016 & 04.18 .2016 & 04.22 .2016 & 06.21 .2016 \\
\hline \multicolumn{6}{|c|}{ Thumb opposition test (tip to tip) } \\
\hline Second finger & $+1-$ & $+/+$ & $+/+$ & $+/+$ & $+/+$ \\
\hline Third finger & $+1-$ & $+/+$ & $+/+$ & $+/+$ & $+/+$ \\
\hline Fourth finger & $+1-$ & $+1-$ & $+1+{ }^{*}$ & $+/+$ & $+/+$ \\
\hline Fifth finger & $+1-$ & $+1-$ & $+1-$ & $+1-$ & $+/+$ \\
\hline Kapandji score & 2 & 4 & $5^{*}$ & 5 & 8 \\
\hline \multicolumn{6}{|l|}{ Grip strength (kg) } \\
\hline Right & 32.0 & & & 32.0 & 41.0 \\
\hline Left & 6.0 & & & 10.0 & 28.0 \\
\hline \multicolumn{6}{|c|}{ Lateral pinch power (kg) } \\
\hline Right & 9.5 & & & 8.5 & 11.0 \\
\hline Left & um & & & 3.0 & 8.2 \\
\hline \multicolumn{6}{|c|}{ Tip pinch power (kg) } \\
\hline Right & 5.0 & & & 3.0 & 7.0 \\
\hline Left & um & & & um & 4.5 \\
\hline
\end{tabular}

um, unmeasurable due to weakness.

${ }^{*}$ Prompt increase in finger power.

the episode showed much improved left-hand strength. Left finger flexion was good grade and extension was fair plus. Two days before seizure, he could oppose his left thumb to the second-third, but not the fourth-fifth fingertips. However, he could easily move his left thumb to the fourth finger tips with much separated movement on April 18, following the post-ictal phase, and the Kapandji score improved from 4 to 5 (Table 2). Although he had no spasticity since the stroke, he showed dysregulated synergic flexion pattern in the left fingers. He could not independently flex his first and second fingers after the stroke, but he could make immediately following the seizure. Grip strength (from 6.0 to $10.0 \mathrm{~kg}$ ) and lateral pinch power (from unmeasurable to $3.0 \mathrm{~kg}$ ) was improved on April 22 compared to March 15. Furthermore, he reported that he could make these movements with greater power within 5 seconds before he lost consciousness.

On April 19, he reported that hand power and coordination were definitely improved compare with prior to the seizure, but not as much as immediately following the post-ictal phase. Finger flexion power decreased to fair plus from good, but this was improved compared to before the seizure.

He transferred to another rehabilitation hospital on April 21, and left upper and lower extremity strength continued to improve. When examined in the outpatient clinic on June 21, strength was improved to good grade in all left-side muscle groups.

\section{DISCUSSION}

There have been numerous attempts to reproduce or regenerate nerves in central nervous system (CNS). CNS neuromodulation research began long before the human stem cell research that began in 1978. Similar to the preceding transcranial direct current stimulation and electroconvulsive therapy, transcranial magnetic stimulation (TMS) raised major ethical concerns. Despite being non-invasive, several side effects were reported, including nausea, epistaxis, dizziness, headache, tinnitus, vision problems, hearing loss, and seizures. The U.S. Food and Drug Administration (FDA) approved TMS in 2008. The FDA subsequently 
issued a "Class II Special Controls Guidance Document for rTMS Systems" including a table named "Maximum Safe Train Duration (seconds) Limits for Avoiding Seizure" on July 26, 2011. Despite this guidance, some clinical reports of high-frequency rTMS which did not follow the protocol demonstrated effectiveness without complications. Khedr et al. [1,2] reported pain relief in trigeminal neuralgia or post-stroke pain syndrome $(20 \mathrm{~Hz}, 80 \% \mathrm{RMT}$, 10 trains, 10-second train duration, 2,000 pulses/session, 5 sessions for 5 consecutive days), and improved motor performance in Parkinson's disease after high frequency rTMS (25 $\mathrm{Hz}, 100 \%$ RMT, 10 trains, 4-second train duration, 1,000 pulses/session, 6 sessions for 6 consecutive days). Ahmed et al. [3] showed phantom pain relief with high frequency rTMS (20 Hz, 80\% RMT, 10 trains, 5-second train duration, 1,000 pulses/session, 5 sessions for 5 consecutive days). Hausmann et al. [4] showed no adverse effect including seizure when applied high frequency rTMS to the depressive patients ( $20 \mathrm{~Hz}, 100 \%$ RMT, 10 trains, 10 -second train duration, 2,000 pulses/session, 10 sessions for $2 \times 5$ days). However, a recent report described a seizure following low-frequency rTMS despite compliance with FDA guidance [5]. In our study, although the therapeutic design ( $20 \mathrm{~Hz}, 90 \%$ RMT, 15 trains, 5 -second train duration, 1,500 pulses/session, 10 sessions for $2 \times 5$ days) was against the U.S. FDA guidance, it was among the previous therapeutic boundary of which the out-of-guideline studies showed promising outcomes or at least not caused severe adverse effects. However, this protocol led to the seizure event. As he had no lesion other than in the basal ganglia, and there had been no epileptic episode, spontaneous seizure was unexpected. Thus, we assumed that the seizure was due to the cumulative effect of rTMS.

Moreover, the patient had no neurologic regression after the seizure, but showed improved muscle strength and hand function. This is distinct from previous reports of seizure following rTMS. Dobek et al. summarized all 25 seizure events reported as of September, 2015, and none showed motor recovery or improved coordination after the seizures [6]. However, there have been some reports of neurologic improvement other than motor recovery. Bagati et al. [7] reported a patient with improvement in depression 3 days after the rTMS-induced seizure. Another case with adolescent-onset major depressive disorder showed hypomania for only 1 night after an rTMS-induced seizure [8]. Whereas, Fauth et al. [9] reported a patient with left middle cerebral artery infarction who had 4 days of postictal paresis. However, the neurologic improvement after rTMS-induced seizure could be a separate sole result of rTMS, not of the seizure. Thus, there can be a logical leap to judge the neurologic improvement as a result of rTMS-induced seizure.

While thumb opposition was tested on April 16 and 18, strength was measured by the devices on March 15, April 22, and June 21. This is a limitation of this report, since the power measurement was not performed closer to the day of the seizure (Table 2). However, considering the results of manual motor test and more separated movement after post-ictal state, prompt measurement also would have shown each improved power, if performed.

As conclusion, this is the first report of prompt motor recovery after seizure induced by high-frequency rTMS. Although this patient showed no other neurologic adverse effects, considering the potential negative consequences of seizure, high-frequency rTMS should be carefully applied based on safety consensus. Through the cumulative results of the protocols which reported with a slightly off-line guideline so far, more precise information for more effective and safe rTMS would be obtained. 


\section{REFERENCES}

1. Khedr EM, Kotb H, Kamel NF, Ahmed MA, Sadek R, Rothwell JC. Longlasting antalgic effects of daily sessions of repetitive transcranial magnetic stimulation in central and peripheral neuropathic pain. J Neurol Neurosurg Psychiatry 2005;76:833-838. PUBMED | CROSSREF

2. Khedr EM, Rothwell JC, Shawky OA, Ahmed MA, Hamdy A. Effect of daily repetitive transcranial magnetic stimulation on motor performance in Parkinson's disease. Mov Disord 2006;21:2201-2205. PUBMED | CROSSREF

3. Ahmed MA, Mohamed SA, Sayed D. Long-term antalgic effects of repetitive transcranial magnetic stimulation of motor cortex and serum beta-endorphin in patients with phantom pain. Neurol Res 2011;33:953-958. PUBMED | CROSSREF

4. Hausmann A, Kemmler G, Walpoth M, Mechtcheriakov S, Kramer-Reinstadler K, Lechner T, Walch T, Deisenhammer EA, Kofler M, Rupp CI, Hinterhuber H, Conca A. No benefit derived from repetitive transcranial magnetic stimulation in depression: a prospective, single centre, randomised, double blind, sham controlled "add on" trial. J Neurol Neurosurg Psychiatry 2004;75:320-322. PUBMED | CROSSREF

5. Agosta S, Galante E, Ferraro F, Pascual-Leone A, Oster J, Battelli L. Report of a delayed seizure after low frequency repetitive transcranial magnetic stimulation in a chronic stroke patient. Clin Neurophysiol 2016;127:1736-1737. PUBMED | CROSSREF

6. Dobek CE, Blumberger DM, Downar J, Daskalakis ZJ, Vila-Rodriguez F. Risk of seizures in transcranial magnetic stimulation: a clinical review to inform consent process focused on bupropion. Neuropsychiatr Dis Treat 2015;11:2975-2987. PUBMED | CROSSREF

7. Bagati D, Mittal S, Praharaj SK, Sarcar M, Kakra M, Kumar P. Repetitive transcranial magnetic stimulation safely administered after seizure. J ECT 2012;28:60-61. PUBMED | CROSSREF

8. Hu SH, Wang SS, Zhang MM, Wang JW, Hu JB, Huang ML, Wei N, Zhou WH, Qi HL, Xu WJ, Xu Y. Repetitive transcranial magnetic stimulation-induced seizure of a patient with adolescent-onset depression: a case report and literature review. J Int Med Res 2011;39:2039-2044. PUBMED | CROSSREF

9. Fauth C, Meyer BU, Prosiegel M, Zihl J, Conrad B. Seizure induction and magnetic brain stimulation after stroke. Lancet 1992;339:362.

PUBMED | CROSSREF 